\title{
OSCILLATIONS OF EVEN ORDER LINEAR IMPULSIVE DELAY DIFFERENTIAL EQUATIONS
}

\author{
LIJUN PAN AND JiNDE CAO
}

Abstract. In this paper, we devote to investigation of even order impulsive delay differential equations, new oscillation criteria for every solution of equations are established.

Mathematics subject classification (2010): 34K06, 34K11.

Keywords and phrases: even order, linear, impulsive delay differential equations, oscillation.

\section{REFERENCES}

[1] T. H. BARR, Oscillations in linear delay differential equations, J. Math. Anal. Appl., 195 (1995), 261-277.

[2] L. BerezAnsky AND E. BRAVERman, Some oscillation problems for a second order linear delay differential equation, J. Math. Anal. Appl., 220 (1998), 719-740.

[3] L. Berezansky and E. Braverman, On oscillation of a second order impulsive linear delay differential equation, J. Math. Anal. Appl., 233 (1999), 276-300.

[4] Y. S. Chen, W. Z. FENG, Oscillations of second order nonlinear ODE with impulses, J. Math. Anal. Appl., 210 (1997), 150-169.

[5] K. Gopalsamy and B. G. Zhang, On delay differential equations with impulses, J. Math. Anal. Appl., 139 (1989), 110-122.

[6] Z. M. HE AND W. G. GE, Oscillations of second-order nonlinear impulsive ordinary differential equations, Comput. Appl. Math., 158 (2003), 397-406.

[7] I. T. KIgURADZE, The capability of certain solutions of ordinary differential equations to oscillate, Dokl. Akad. Nauk. SSSR, 144 (1962), 33-36.

[8] V. Lakshmikantham, D. D. Bainov, P. S. Simeonov, Theory of impulsive differential equations, World Scientific, Singapore, 1989.

[9] J. W. LUO AND L. DEBNATH, Oscillations of second order nonlinear ordinary differential equations with impulses, J. Math. Anal. Appl., 240 (1999), 105-114.

[10] L. J. PAN, G. Q. WANG AND S. S. CHEN, Oscillation of even order nonlinear differential equations with impulses, Funkcialaj Ekvacioj, 50 (2007), 117-131.

[11] G. H. RYDER AND V. V. WEND, Oscillation of solutions certain ordinary differential equations of $n$-th order, Proc. Amer. Math. Soc, 21 (1970), 463-469.

[12] W. TRENCH, An oscillation condition for differential equations of arbitrary order, Proc. Amer. Math. Soc, 82 (1981), 548-552.

[13] J. R. YAN, Oscillation of nonlinear delay impulsive differential equations and inequalities, J. Math. Anal. Appl., 265 (2002), 332-342.

[14] Y. Z. ZHANG, A. M. ZHAO, J. R. YAN, Oscillation critera for impulsive delay differential equation, J. Math. Anal. Appl., 205 (1997), 461-470. 